\title{
O QUE SIGNIFICA SER ESTADO NUMA EPIFANIA PROCESSUAL PENAL? A HERMENÊUTICA FILOSÓFICA FRENTE O PROCEDIMENTO REPRESSIVO COMO REFÉM IDEOLÓGICO
}

\author{
WHAT DOES IT MEAN TO BE AN STATE IN AN EPIPHANY CRIMINAL \\ PROCEDURE ? PHILOSOPHICAL HERMENEUTICS AND REPRESSIVE \\ PROCEDURE AS IDEOLOGICAL HOSTAGE
}

${ }^{1}$ Bruno Gadelha Xavier

\section{RESUMO}

O presente artigo tem como fulcro essencial a discussão da definição do processo penal no contexto do Estado Democrático de Direito. O que se observa da realidade é um discurso que se exime de apontar a ingerência ideológica no conhecimento do aparato repressivo, o que, indubitavelmente, gera o reconhecimento da importância da hermenêutica frente à máquina estatal. A discussão sobre o papel do procedimento inquisitivo-acusatório nacional gera impacto direto na concepção de Teoria do Estado contemporânea, razão pela qual é imperioso o questionamento.

Palavras-chave: Processo penal, Ideologia, Estado democrático

\section{ABSTRACT}

This article has the essential fulcrum the discussion of the definition of criminal proceedings in a democratic state. What is observed in reality is a discourse that is failing to point the ideological interference in the knowledge of the repressive apparatus, which undoubtedly raises the recognition of the importance of hermeneutics against the machine state. The discussion on the role of the inquisitorial-accusatory Brazilian procedure generates direct impact on the design of the contemporary Theory of State, which is why the question is imperative .

Keywords: Criminal procedure, Ideology, Democratic state

\footnotetext{
${ }^{1}$ Doutorando em Direitos e Garantias Fundamentais pela Faculdades de Direito de Vitória, FDV - ES, (Brasil). E-mail: brunogadelhaxavier@hotmail.com
} 


\section{INTRODUÇÃO}

A mesma estória é contada em diversos cursos de Direito pelo país: quando alguém comete algum ato típico, antijurídico e culpável, ou seja, um acontecimento que fere bem jurídico tutelado por legislação penal, exsurge, por parte do Poder Público, o jus puniendi, o direito de punir.

Ao final do procedimento acima destacado, irá se observar se convém, ou não, a aplicação de uma sanção. Afinal, o Estado contratualista moderno detém o monopólio da vis física, e da juris dictio.

Tais aportes conceituais servem muito bem para uma explanação inicial do fenômeno processual penal nas faculdades, entretanto, não é preciso ao conceituar a realidade do procedimento repressivo em terrae brasilis. Há a tortura das figuras mitológicas de Dikê e Têmis, posto um sistema que é seletivo, e não funciona igualitariamente para todos, muito menos está calcado em mera lógica matemática do processo penal. Necessária, portanto, uma epifania do objeto em tela, a fim de aferir sua verdadeira essência.

Indiscutivelmente, ao se analisar o sistema repressivo atual, a conclusão que deve-se chegar é que o paradigma constitucional ainda não foi concretizado - e, provavelmente, mesmo com um novel Código Penal ainda não o será. Um notório fracasso aos estudiosos da questão, posto que a práxis informa ser a gama repressiva um instrumento de controle social de segregação, servindo a funções outras, a depender da orientação ideológica de quem está julgando.

Para tanto, irá se reconhecer da insuficiência terminológica na definição da maioria da doutrina e jurisprudência, e submissão de todo o aparato repressivo à ideologia do intérprete. Ou seja, é reafirmar a lógica subjetiva no aplicar do Direito, no caso em comento, da gama repressiva penal.

E, justamente, por ser refém da ideologia, o processo penal acaba apresentando uma dualidade inerente à sua própria existência com excessos infundados, traduzidos em proteção deficiente e proteção exacerbada. Neste condão teórico, como ficaria a posição do Estado, ou melhor, como enquadrar tal questionamento em um aparato teórico no qual tome a Teoria do Estado contemporâneo como norte a ser desconstruído?

Como conciliar tais temas basilares e concluir um processo democrático no Estado de Direito? Sem dúvidas, um questionamento que traz uma discussão que deve ser dilapidada, 
pormenorizada, com o fulcro de obter uma razão concreta do que venha a ser o processo penal brasileiro.

\section{O PROCESSO: POR UMA REALIDADE "NÃO-KAFKANIANA"}

Nas palavras de Pontes de Miranda (1995, p. 191), "processo é pôr em sequência atos e atividades, para que se atinja algum fim. No processo jurídico, o que se tem por fito é a decisão, sentença ou acórdão”. Neste sentido, ainda que seja relatada uma concepção de teoria geral do processo, não devemos olvidar: processo é garantia do cidadão frente o aparato público.

Justamente a fim de superar o deletério Estado de Natureza (ficto, mas substancial elemento da retórica contratualista), os homens se agrupam e forjam (o também ficto, mas vinculante) contrato social, superando a negatividade do momento anterior, o que Bobbio (1994, p. 19) asseverou como o momento supremo e definitivo da vida comum e coletiva do homem, ser racional, assim como o resultado mais perfeito ou menos imperfeito daquele processo de racionalização dos instintos ou das paixões ou dos interesses, mediante o qual o reino da força desregrada se transforma no reino da liberdade regulada.

Exsurge o Estado, que avocou, para si, o controle social, a manutenção da vida em sociedade. Possuindo seus meios de coerção, o detentor do monopólio da força física acaba por impor, ao indivíduo que "quebrar", "desrespeitar", a lei, a devida sanção kelseniana (1998, p. 37), ou seja, uma reação contra o indivíduo pela mesma ordem jurídica que especificou ser a conduta antijurídica uma forma de ensejar uma resposta estatal. A sanção, por sua vez, deve, indubitavelmente, ser aplicada ao cidadão de forma racional, pela via de um processo frente o ente público. No caso de condutas que ferem bens jurídicos tutelados pela legislação penal, tem-se o processo penal.

Ao se observar a postura doutrinária frente a definição do objeto do processo penal, de fato, pode-se concluir que a maioria das concepções da dogmática processual criminal apontariam o processo penal como conjunto de normas jurídicas válidas, vigentes e eficazes que regulamentam e legitimam modus operandi do jus puniendi estatal, em plano abstrato. Apresenta-se, por conseguinte, o poder punitivo concretizado por parte da máquina estatal quando há a atuação de indivíduo no sentido de lesionar o bem jurídico resguardado sub lege penal (na observância do necessário princípio da anterioridade), e, observância, deste fato, por parte do Poder Público. 
Pelo processo penal, almeja-se concretizar a pretensão punitiva, assumida racionalmente pelo Estado após longo processo evolutivo, submetendo o infrator às sanções da norma, e fazendo com que os órgãos estatais atuem - se for o caso - em prol do resultado coator. Que se observe o magistério de Günther Jakobs (1998, p. 33):

\begin{abstract}
El derecho penal tiene la misión de garantizar la identidad de la sociedad. Eso ocurre tomando el hecho punible en su significado, como aporte comunicativo, como expresión de sentido, y respondiendo ante él. Con su hecho, el autor se aferra a la afirmación de que su conducta, esto es, la defraudación de una expectativa normativa, integra la conducta determinante, y que, entonces, la expectativa normativa en cuestión es un accesorio no determinante para la sociedad. Mediante la pena se declara, contra esa afirmación, que ello no es así, que, antes bien, la conducta defraudatoria no integra, ni antes ni ahora, aquella configuración social que hay que tener en cuenta.
\end{abstract}

O conjunto de etapas procedimentais, em sede penal, como qualquer processo, não pode se esquecer de sua inserção em sede de Estado Democrático de Direito. De certo, tem-se uma eterna colisão: o punir dos atores sociais repressivos (desde uma criminalização primária pela lex, à criminalização secundária das agências sociais), versus a o status libertatis. Patente, portanto, o kratos tensional entre a repressão e a liberdade, que culmina na eterna aporia penal: como punir?

O que se observa do supra é, justamente, o construir discursivo baseado em uma idéia de processo matematizada. Tal "matematização" processual é, apesar de amplamente adotada pela doutrina, equivocada. É falaciosa e desconsidera a realidade, justamente pelo fato de que o Direito, um "magma de significações" (vênia a Castoriadis), não pode ser reduzido a uma estrutura equacional de ciência exata. Ora, ninguém reflete que a equação pode estar a serviço de quem determina os pesos das variantes?

Ademais, alguém teria a coragem de denunciar a matematização de uma decisão? A ausência de um conteúdo reflexivo que resulte de uma operação hermenêutica real - a ser tratada mais a frente pela via da hermenêutica filosófica - acarreta em um "Boulevard de incongruências decisionais", ou na inflação do ethos e do pathos. Alexandre Morais da Rosa (2011, p. 131) indica um diálogo que acaba por reforçar a noção de que não se busca o conteúdo, e sim a legitimidade pelo simbólico poder de um exoesqueleto (in)visível:

Diálogo entre dois magistrados: “- Concordas com a decisão?" "- Sim, se for do Supremo.” Responde o Juiz que decide conforme a moda. “- Mas e o conteúdo, você concorda?" Pergunta o primeiro magistrado. "- E precisa? A embalagem me satisfaz." 
Neste sentido, cabível mencionar que o processo (in casu, o penal), está refém da ideologia de quem o propõe, aplica. Tal imposição ideológica gera grave bipolaridade no sistema: a relatada punição exacerbada ou liberdade desmedida. Complementa-se, a título de elucidação, que o conceito de ideologia adotado remonta lição de Antônio Carlos Wolkmer (2003, p. 109):

Fica claro, a partir de agora, que não obstante a complexidade de uma conceituação do fenômeno ideológico, toda ideologia é, por conseguinte, não só o reflexo simbólico permanente das condições e representações ético-culturais reais e imagináveis, como também da própria racionalização e legitimação de uma estrutura socioeconômica que predomina em determinado momento histórico-político.

A imprecisão é prejudicial, indubitavelmente, pois gera um loco de anomia. Observe: os excessos não estão previstos sub legem, portanto, sua existência no proferir do Estado-juiz é ilegal, e muitas vezes inconstitucional. Imputa-se a uma questão ideológica o modus reflexivo do aparato processual penal. Ou seja, na práxis, a ratio do intérprete, que desde cedo introjeta seus axiomas referentes à pena, ao Estado, à lei, dentre outros elementos basilares, é que irá determinar a fundamentação do decisum repressivo.

Confirma tal face acrítica da decisão penal, a recorrente crítica de autores como Lenio Streck (2013, p. 40-47), qual seja, o fato de que as (ditas) faculdades de Direito (ainda) apresentam mazelas quanto ao ensino jurídico. Ficam vinculadas a posicionamentos meramente legalistas, baseados em doutrinas que se apresentam demasiadamente rasas, ou ideologicamente comprometidas. Isso sem mencionar os cursos preparatórios e pós- graduações fajutas (que por si só, merecem uma crítica à parte).

Culmina, portanto, na indagação: afinal, quem possui o dolus malus, o Estado ou o indivíduo? Nunca saberemos a resposta ao certo, entretanto, postula-se, desde já, uma afirmação: realizar uma unilateralidade do processo penal, um maniqueísmo agravado, é deixar incidir um discurso vazio no ambiente jurídico, e conseqüente impacto na prática jurídica.

Desta forma, necessário se faz - para evitar uma realidade Kafkaniana (vide "O processo", 2002), ou até mesmo, uma descrença Zolaiana (conforme "Eu Acuso!: o Processo do Capitão Dreyfus”, 2007) - indagar, como Roxin (2001, p. 406), sobre o futuro desse mal necessário, o âmbito penal conforme este é visto hoje. 


\title{
2 DA (TÃO DEBATIDA) SELETIVIDADE SISTÊMICA: A TORTURA DE DIKÊ E TÊMIS E SEU IMPACTO NA CONCEPÇÃO ESTATAL DO QUE É PUNIR
}

Justamente por ser refém da ideologia, o processo penal tem sua definição atrelada ao simulacro subjetivo do intérprete/autor/aplicador do Direito. Punitivismo e garantismo, "ismos" a serviço da clara seletividade sistêmica. Com muita propriedade ensina Eugenio Raúl Zaffaroni (1996, p. 246-247), o desconhecer da teoria do delito da realidade a qual é aplicada:

\begin{abstract}
"O" delito não existe. A parte especial de qualquer código penal elenca uma quantidade de ações conflitivas totalmente heterogêneas quanto ao seu significado social. [...] Resulta bastante evidente que esta disparidade de hipóteses e de reações ao sistema penal não podem dar lugar a nada unitário. Entretanto, o discurso jurídico-penal parece desprezar estes dados, oferecendo um "conceito unitário" de delito, mediante uma complexa elaboração teórica denominada, usualmente, de "teoria do delito", que afirma (com algumas variações, conforme seu autor) que "delito é ação típica, antijurídica e culpável”.
\end{abstract}

Repare, a argumentação está a serviço de quem detém o iuris dictio, assim sendo, por um espeque seletista, podemos ter, pelo mesmo magistrado, a dualidade acima destacada em decisões acerca de delitos distintos. Não há como afirmar, objetivamente, que um magistrado é "inquisitório-utilitarista" ou garantista, podendo ele conviver com sua razão fundamentada pelo excesso nos dois lados, conferindo muito mais uma decisão política que jurídica. Daí as crescentes discussões criminológicas sobre a criminalização secundária judicial pré-moldada a serviço do discurso de quem tem, efetivamente, o poder na sociedade.

O douto julgador utiliza de elementos argumentativos para moldar uma decisão que, claramente, não possui fundamento, dando uma resposta à sociedade, e construindo uma falaciosa sensação de segurança. Aparenta, muitas vezes, não saber da gravidade de seus atos, sobre o objeto que o processo penal tutela, e a sanção por excelência que é dada ao infrator, qual seja, a pena privativa de liberdade. Esta, por sua vez, com todos os seus efeitos declarados (e não-declarados), que moldará a vida de um indivíduo, que trará um destino com uma súplica estrutural inerente ao sistema carcerário nacional.

O fato acima destacado faz com que pensamos em que ordem jurídica estamos vivendo. Como é plausível a inobservância da sociedade se, justamente, esta é a julgada. A falta de tato social, conhecimento das situações, conjuntamente a posturas preconceituosas fazem com que 
o Direito, na visão de alguns magistrados, seja quase um título de romance: Orgulho e Preconceito (distinto, obviamente, da estória original do romance inglês de Jane Austen).

Orgulho é o ego decisionista, tantas vezes moldado pela jurisprudência de tribunais superiores, ou, moldados da jurisprudência dos tribunais inferiores. Sem dúvidas, conferir poder a alguém é saber que excessos, muitas vezes, serão cometidos, o grave receio é quando estes passam de exceção à regra. Preconceito porque, justamente, é posto na decisão o "poder da Medusa" ideológico, transformando em "pedra" a ratio decisione tendenciosa e selestista, construindo um inimigo a ser combatido.

A postura gera um descrédito na Justiça, a terrível tortura de Dikê e Têmis. Qual cidadão quer se submeter a tal nível de discricionariedade desmedida, ou melhor, os Palácios de Justiça viraram um jogo randômico na qual a sorte está lançada?

Não restam dúvidas, o processo penal deve se assumir como efetivamente é, apenas assim conseguiremos uma sociedade justa. Desta feita, o fenômeno processual é, como afirma Rafael Tomaz de Oliveira e Lenio Luiz Streck (2012, p. 21-22), uma ciência hermenêutica, o que significa dizer que os operadores processuais se ocupam da compreensão e da interpretação de textos legais do espeque processual penal e de fatos concretos, reconstruídos a partir do discurso posto no procedimento. Desta feita, a possível crítica somente ocorrerá quando observarmos que o correto encaminhamento das questões dispostas ao contexto processual penal reivindica o reconhecimento deste como atividade interpretativa.

Insta relacionar o reconhecer da importância interpretativa na (ainda que mito) verdade real, a fim de aferir da realidade fática a conclusão punitiva (ou não). O utilizar dos elementos probatórios e linguísticos para pôr, em sede processual, uma conclusão lógica. Resguardando, dentre outros, a falha memória humana e a verdade dos acontecimentos. Entretanto, a interpretação carece de uma razão coerente (em termos constitucionais). Cria-se um panóptico benthaniano decisionista, no qual se realiza, por meio de uma hermenêutica infundada, o controle social classista. Em outra lição, é mencionar que se faz um discurso incoerente pautado em "interpretações justas" - e não constitucionalmente adequadas-, alimentada por um ditame de medo social e segregação pessoal, entretanto, o que se tem é uma hermenêutica maculada, viciada em sua origem por pré-visões, que acarretará uma fundamentação também prejudicada. 
Que se diga: além de problema de cunho hermenêutico, da visão interpretativa que é dada pelo Estado-juiz ao caso concreto, o problema também é argumentativo, da justificação da sentença.

Ora, na criminalização secundária reforça-se os ditames inquisitoriais previstos outrora por uma criminalização primária que carece de uma cosmovisão democrática, em prol de uma subserviência a uma cultura do medo neoliberal que propõe criminalização em massa e se vale dos instrumentos jurídicos para gerar o imaginário social (na expressão de Cornelius Castoriadis) punitivo caboclo.

Por esse label, essa rotulação demasiada, se julga previamente certos indivíduos, os homo sacer, os inimigos, nossos brazilian outsiders, na medida em que esse selecionado alguém não se "comporta" nas regras do grupo (BECKER, 2008, p. 15). Nossa "cifra oculta" é deletéria, preconceituosa, segregadora, mas cumpre seu papel de espelho ideológico de uma pólis que teve seus valores democráticos subvertidos.

Como resolver? A solução é repensar o pensar. Criticar a interpretação, a fundamentação. É pela face da razão que se terá uma resposta correta (quanto a sua constitucionalidade). Neste espeque, Hans-George Gadamer, tem grande importância na hermenêutica filosófica do Estado Democrático de Direito. A resposta é uma inerente alteridade do texto a ser observado. O reconhecer e superar do pré-conhecido, do pré-axioma, do préjuízo, uma vez seu conhecimento prévio não ser arbitrário, retomando uma faceta da vis reflexiva gadameriana, propondo, assim, um processo interpretativo sem as ingerências dos valores de uma socialização tendenciosa, com a devida visão da sociedade, nos moldes de uma justiça social coesa.

Afirma Gadamer (1997, p. 489) que a meta da interpretação apresenta-se na concretização da lei em cada caso (a aplicatio), de modo que na sentença do juiz não surja arbitrariedades imprevisíveis, mas uma ponderação justa de conjunto. Assim, é essencial reconhecer a observância da Constituição como filtro necessário do sistema, bem como instrumento de aplicação direta prima facie. Não resta cabível os "prejuízos inautênticos" (no sentido Heideggeriano da expressão) frente à necessidade de concretização da Carta Política, como bem ensina o magistério de Nelson Camata Moreira (2012, p. 176):

Esta (so)negação dos direitos fundamentais encaixa-se, numa análise filosófica, naquilo que Heidegger chamou de prejuízos inautênticos, os quais contaminam a capacidade compreensiva do intérprete, na medida em que impedem que o ser que se compreende (Dasein) consiga des-velar adequadamente o ser da Constituição, 
instauradora do Estado Democrático de Direito. A visão engessadora dos ditames da nova ordem jurídica estabelecida a partir de 1988 acaba contribuindo para a reprodução de conceitos (Decaída para Heidegger), quando na verdade, a partir de uma proposta hermenêutica, deveria ocorrer a produção de sentido do intérprete.

Outrossim, em sede do atual Constitucionalismo, devemos repensar a função principiológica - sempre cauteloso com a possibilidade de uma "panprincipiologia" sisífica calcando-a a uma dimensão normativa. De certo, não podem mais ser vistos como simples instrumentos de solução da lide em casos de insuficiência legal ou sistêmica, e sim como constituidores de normatividade, emergindo da concretude dos problemas dispostos no Judiciário. Ou seja, uma decisão judicial adequada se baseia em uma comunidade de princípios (OLIVEIRA, STRECK, 2012, p. 11).

É fundamental no construir do sentido, o visualizar de um "tipo ideal": conseguir sair do que Warat (1994, p 15) denominou de "senso comum teórico dos juristas", dos topoi que apenas servem como instrumento de controle social indevido.

Que não se olvide, a doutrina atualmente conjuga o devido processo legal com a idéia de um processo justo, a fim de concretizar um processo idôneo a todos. O Estado tem dever de tutelar de forma justa os direitos de todos, concretizando a pretensão jurídica (Justizanspruch) e a pretensão da tutela jurídica (Retchsschutzanspruch). O neoconstitucionalismo derivado de uma revolução copernicana do direito público prega pelo respeito à ordem constitucional, fulcro fundamental que não deve ser suprimido.

Ademais, não há processo sem a devida motivação do julgado. Não há contraditório sem a devida motivação, ou seja, suprimem-se garantias, justamente, pela ineficiência do Judiciário. O exercício da jurisdição é sim uma questão de vida ou morte, os reais e simbólicos laços de confiança do cidadão com o Judiciário não podem ser rompidos, sendo o primeiro assistido por uma ordem justa, constitucional, sem erros grosseiros, anestesiando o medo do jurisdicionado frente ao Leviatã.

A figura da sentença (sententia) advém como gerúndio do latim sentire, que significa sentir, e possui uma importância muito maior do que é dada muitas vezes por doutrina e jurisprudência, justamente por ser a via de atribuição de sentido ao texto, ou seja, é a imposição do poder estatal em forma linguística, com consequente condenação ou não do indivíduo. Nada mais certo, portanto, devido à importância dada à decisão judicial, o obervar de uma via de mão dupla: não apenas decisões fundamentadas, mas decisões justas. 


\section{3 ÜBERMASSVERBOT $\mathrm{x}$ UNTERMASSVERBOT: SERIA A LEITURA NOS DITAMES DA VERFASSUNGSKONFORME AUSLEGUNG VON GESETZENO MODO PELO QUAL O ESTADO MODERNO DEVERIA REALIZAR SUA PUNIÇÃO?}

Desde priscas eras, é sabido que o ser humano, como ser racional, pensante, é falho. Um vivente que é sempre alvo de excessos em sua vida. Em outras palavras, o cotidiano humanista presente no cronos histórico demonstra a socialização de valores, o aprendizado, justamente no medir de suas ações, desde o déficit ao excesso. Os grupos de referência normativos negativos compõem, neste sentido, a carência e o exacerbar, para, justamente, criar um grupo de referência normativo positivo que seja necessário ao ser humano para descobrir um lidar coerente com os elementos sociais.

Lembremos-nos do giro linguístico de Ludwig Wittgenstein, com o respeito à linguagem, posto esta ser condição de aprendizagem e articulação de todas as coisas, em outros termos, tudo fora da linguagem é inconcebível à reflexão cognitiva humana. A partir do marco teórico de "Investigações Filosóficas", Wittgenstein é tido - ao lado de Heidegger como um dos pilares de necessária observância na crítica a filosofia da subjetividade. Pela noção de que não há um mundo em si que consiga ser independente da linguagem, esta escapa de ser um mero instrumento a fins de comunicação do conhecimento, e agrega a função de condição de possibilidade da própria constituição do conhecer (STRECK, 1999, p. 144).

Justamente em sede lingüística, os alemães foram felizes ao elencarem na dualidade eterna pós-contrato social do maquinário penal estatal, as expressões "proibição de excesso" (Übermassverbot) e "proibição de proteção deficiente" (Untermassverbot), a fim de demonstrar perfeitamente pela via léxica o paradoxo repressivo, unindo significado e significante. Streck (2004, p. 250), com sua tempestividade teórica, demonstra sobre as expressões:

Nesse sentido, se de um lado há a proibição de excesso (Übermassverbot), de outro há a proibição de proteção deficiente (Untermassverbot). Ou seja, o direito penal não pode ser tratado como se existisse apenas uma espécie de garantismo negativo, a partir da garantia da proibição de excesso. Com efeito, a partir do papel assumido pelo Estado e pelo Direito no Estado Democrático de Direito, o direito penal deve ser (sempre) examinado também a partir de um garantismo positivo, isto é, devemos nos indagar acerca do dever de proteção de determinados bens fundamentais através do direito penal. 
Resta claro a mazela processual penal de vinculação à ideologia, que reflete em uma práxis, conforme já explicitado, exacerbada. Seja um garantismo (apesar de reconhecidamente ser uma teoria louvável, com aplicabilidade necessária no Estado Democrático de Direito) desmesurável e infundado, excessivo e concretizador de uma proteção deficiente, até uma punição (mesmo respeitando os ditames do princípio da vedação da proteção deficiente) utilitarista desmedida. Há de se concretizar uma ponte entre os postulados, evitando os excessos, um meio razoável-racional.

Trata-se de uma questão de probidade jurisdicional, de bom uso da res pública, da máquina pública que move a segurança da pólis e a vivência em sociedade com direitos e garantias.

Passa-se a questão: como proceder a resolução da imprecisão do objeto? Em outras palavras, o que é e como aplicar o processo penal? Como combater sentenças e acórdãos vergastados e hostilizados?

Calha tracejar a resposta, inicialmente, reconhecendo, como já afirmado, o espeque penal como uma atividade hermenêutica. É imperioso tal reconhecimento, mesmo porque, podese (e deve-se) atrelar à retórica matemática da definição do processo (ainda que vetusto) o fator hermenêutico, desconstituindo a falácia de isonomia valorativa entre punição e liberdade.

Em um segundo momento, vale trazer à baila conclusiva o reconhecer da presença ideológica na definição e aplicação do processo penal. Ora, clara cincada afirmar a inexistência de pré-concepções - de certo prejudiciais - ao pronunciamento jurisdicional (ferindo, dentre outros, a tão prezada igualdade material presente no artigo $5^{\circ}$ da Carta Política vigente), Que se relembre, a hermenêutica filosófica gadameriana tem mister importância no primeiro e segundo âmbito de análise, justamente para desconstituir pré-concepções equivocadas e maculadas por ideologias extremistas, de axiomas prejudiciais à uma decisão justa.

Outrossim, a limine, repensar pela via do reconhecimento da importada interpretação conforme a Constituição (Verfassungskonforme Auslegung Von Gesetzen). Ou seja, é reconhecer do garantismo como teoria vigente, entretanto, sem abusos. Reafirmar que toda interpretação deve ser de acordo com os ditames constitucionais, e observada as peculiaridades de cada caso concreto, afinal, todos os magistrado devem realizar controle sobre a constitucionalidade da decisão. Tal ensinamento é irreprochável e implausível de eliminação no Estado Democrático de Direito. Pensar constitucionalmente é viver constitucionalmente, que sejam elucidativas as palavras de (STRECK, 2009, p. 212): 
Comportar-se constitucionalmente é, pois, resistir constitucionalmente. Um comportamento constitucional implica compreender a Constituição existencialmente, enquanto presença constante no nosso cotidiano e no nosso labor jurídico. É compreender que sempre estamos a fazer juízos acerca da (in) constitucionalidade de qualquer ato que tenha relevância jurídico social. E tenhamos claro que, no campo da aplicação do direito, sempre fazemos jurisdição constitucional. Quando examinamos um texto, este já nos vem filtrado pelos nossos pré-juízos, que podem ser legítimos (verdadeiros) ou ilegítimos (falsos). Um comportamento constitucional não permite que o direito - que é sempre "direito constitucional" (assim como um ser é sempre um ser de um ente) - seja transformado em uma mera racionalidade instrumental, ou algo do qual os juristas possam livremente dispor, para fazer emendas, reformas, interpretações despistadoras e outras manobras que visem a enfraquecer a força normativa da Constituição. Em síntese, a destruição da própria constituição.

Ignávia a decisão judicial que se apresentar contrária a Constituição, ao pináculo da ordem jurídica pátria. Dos logogrifos da realidade fática levados ao juízo, afirma-se da necessidade de uma visão jurídica respeitável, correta, o inusitado da realidade leva à criação coesa judicial. Como afirma o professor João Maurício Adeodato (1989, p. 151), é lidar com o que não se lidou ainda, in verbis: "O juiz não pode se limitar a subsumir dedutivamente o particular no geral ou a estabelecer interpretações extensivas, ele precisa decidir sobre o inusitado, que é sempre uma possibilidade na teia das relações humanas".

Devem todos os intérpretes da Constituição atuar em prol desta, retirando do processo sua face de refém de uma ideologia, e reconhecendo este como exercício de poder democrático, sem excessos, e devidamente fundamentado.

O excesso cria o "inimigo" de Jakobs, o "homo-sacer" de Aganbem, o sujeito de não-direito. Transforma a "sociedade aberta de intérpretes da Constituição" de Häberle em um agrupamento seletivo e destruidor de qualquer ordem coesa e justa. $\mathrm{O}$ dilema da garantia versus repressão sempre existirá na ótica constitucional, como disserta Aury Lopes Jr. (2008, p. 125-126): "Considerando que risco, violência e insegurança sempre existirão, é sempre melhor risco com garantias processuais do que risco com autoritarismo". Portanto, deve-se evitar os excessos por parte dos dois lados, como afirma Lênio Streck e Rafael de Oliveira (2012, p. 22-23), o devido processo legal - enquanto garantia - traz, para dentro do direito, axiomas que dizem respeito à moralidade da comunidade política ${ }^{1}$, bem como do dever de equanimidade, igualdade e "justiça", por parte do proferimento estatal;

\footnotetext{
1 Na esteira de pensamento de Ronald Dworkin, pode-se observar obras como "A justiça de Toga", no qual afirma o autor que o Direito pode ser encarado como um branch (ramo) da moral - no sentido de ser uma espécie de pormenor do discurso moral (OLIVEIRA e STRECK, 2012, p.11). Neste espeque, afirma Dworkin (2010, p.51): “[...] o direito como um segmento da moral, não como algo separado dela. Entendemos a teoria política desta forma: como parte da moral compreendida em termos gerais, porém diferenciadas, com sua substância específica, uma vez que aplicável a estruturas institucionais distintas."
} 
entretanto, tais elementos não podem servir para estabelecer excesso na punição, e nem deficiência na persecução, de modo que o dilema do processo penal está, sem dúvidas, calcado sob a alcunha de dois princípios: proibição do excesso (Übermassverbot), e proibição de proteção deficiente (Untermassverbot).

Complementa os autores:

\begin{abstract}
Ou seja, por vezes - e parece ser a maioria - o Estado exorbita no seu poder de punir, devendo ser contido pela possibilidade de, contra ele, esgrimir-se o escudo contra o excesso; já em outras ocasiões, o Estado fica aquém desse dever, tornandose leniente e, com isso, violando direitos fundamentais por não protegê-los suficientemente.
\end{abstract}

E que se trate com cautela o discurso, o qual muitos discorrem, e que poderia ser observado na colisão dos princípios supracitados, da proporcionalidade aplicada às medidas processuais penais. Esta, como instrumento para justificar medidas repressivas ou não, sob o vértice da colisão principiológica dos casos concretos é uma figura jurídica perigosa, afinal, muitos aplicadores da norma ponderam sem o menor critério, confirmando a visio ideológica, e argumentando excessos. Importamos a teoria da doutrina alemã, e aplicamos de maneira equivocada, confundindo-a com ativismo judicial, e conferindo à subjetividade jurisdicional um poder-fazer criativo ilimitado, uma discricionariedade que leva a arbitrariedade (justamente o que Dworkin [1999, p. 55-56] combate quando constrói sua ideia de "aguilhão semântico").

Conclui-se, portanto, que o processo penal deve, a partir da teoria levantada, ter suas balizas na Constituição, esta sendo um instrumento (instrumentalidade do processo penal), a fim de o tornar mais justo e democrático, mas, principalmente, sob a observância correta do conflito entre Übermassverbot e Untermassverbot, com a devida equidade. A Teoria do Estado contemporânea, a partir deste condão, refletir sobre o denominado Ius Puniendi, transformando em um juízo constitucionalmente coeso e adequado, à luz de uma Teoria dos Direitos Fundamentais própria do ambiente Democrático.

\title{
CONCLUSÃO
}

A pós-modernidade foi cruel com o direito e processo penal. O que se observa hoje é um cansaço, um desânimo, devido à má-utilização, pela via racional-legal e em sua aplicabilidade prática, do aparato punitivo. 
Ora exarcebado, ora defeituoso, o jus puniendi estatal é, certamente, uma faceta curiosa do poder do maquinário público. Questionar a razão de punir, quem punir, como punir é só o início de uma discussão jurídico-filosófica da própria essência da máquina pública. Afinal, como se proteger das arbitrariedades daquele que supostamente deveria tutelar nossa vida com seguridade e conferindo acesso aos direitos e garantias básicas do cidadão?

Em que pese não encontrar na doutrina e jurisprudência definições que valorizem a função hermenêutica no processo penal, ela está presente. Justamente pela via interpretativa (e argumentativa), que se possibilitará um reconstruir da visão do procedimento repressivo. E, corretamente, uma hermenêutica que se diga constitucional não pode desconsiderar que é mandamento da Carta Política a fundamentação das decisões.

A questão dos excessos deve ser o norte cautelar, a fim de aferir se o posicionamento jurisdicional está ou não a serviço de uma faceta ideológica prejudicial, afinal, a decisão judicial é instrumento da Democracia, e uma vez maculada faz com que se perca a crença na probidade (que não é dever individual do Estado, e sim de todos) outrora conferida ao Estado de Direito.

Não se deve, em nenhum momento, admitir o criar de inimigos, de sujeitos de nãodireito, frente uma sociedade que se diz intérprete da Carta Magna vigente. É um retrocesso social a presença de elementos que justifiquem medidas que desconsiderem as garantias $\mathrm{e}$ direitos do indivíduo, bem como que desconsiderem uma proteção proba da sociedade.

Ademais, o embate entre Übermassverbot e Untermassverbot deve ser lido sempre, no caso concreto, pelo postulado da Verfassungskonforme auslegung von gesetzen, afinal, se estamos em um Estado Constitucional, a resposta correta é aquela que for de acordo com os ditames de uma Constituição viva e eficaz. Questiona-se, por certo, se queremos realität (realidade) ou speicher (memória) constitucional.

Assim, resulta na esperança de se pensar para além do senso comum teórico dos juristas (Warat), em busca de um processo penal que respeite o espaço democrático instituído pelo paradigma constitucional brasileiro pós- 88 , em busca de uma ritualística procedimental que escape de uma postura inquisitorial, garantindo uma hermenêutica ativa na concretização de direitos fundamentais.

Neste prisma, o garantismo deve continuar servindo de norte para a aplicação do direito (não somente o direito penal). Entretanto, calha repensar a fim de evitar os excessos. O excedere é prejudicial não apenas ao cidadão, mas a todo o Estado como unidade organizacional justa e proba que deve ser. Mais do que isso: todo direito a quem dele precisar, toda justiça a quem dela sofrer por, toda igualdade àqueles que necessitarem. Cada cidadão detém o direito de ter 
respostas corretas do ponto de vista constitucional, sem excessos de ambos os lados, e sem ser refém de ideologias das quais prejudicam o andar regular da jurisdição.

\section{REFERÊNCIAS}

ADEODATO, João Maurício. O problema da legitimidade: no rastro do pensamento de Hannah Arendt. Rio de Janeiro: Forense Universitária, 1989.

BECKER, Howard Saul. Outsiders: estudos de sociologia do desvio. Rio de Janeiro: Zahar, 2008.

BOBBIO, Norberto. O conceito de sociedade civil. Rio de Janeiro: Graal, 1994.

DWORKIN, Ronald. O império do Direito. São Paulo: Martins Fontes, 1999.

A justiça de Toga. São Paulo: Martins Fontes, 2010. GADAMER,

Hans-George. Verdade e método. Petrópolis: Vozes, 1997.

JAKOBS, Günther. El sistema de imputacion juridicopenal. In: JAKOBS, Güther;

STRUENSEE, Eberhard (Org.). Problemas capitales del derecho penal. Buenos Aires: Editorial Hammurabi, 1998. p.33-55.

KAFKA, Franz. O processo. São Paulo: Martin Claret, 2002.

KELSEN, Hans. Teoria pura do direito. 6 ed. São Paulo: Martins Fontes, 1998.

LOPES JÚNIOR, Aury. (Re)Descobrindo as Teorias Acerca da Natureza Jurídica do Processo (Penal). Revista Brasileira do Instituto de Ciências Criminais, São Paulo, n. 75, p.119-132, 2008.

MIRANDA, Pontes de. Comentários ao código de processo civil. Tomo I. Arts.1 a 45.3 ed. Rio de Janeiro: Forense, 1995.

MOREIRA, Nelson Camatta. Direitos e garantias constitucionais e tratados de direitos humanos. Belo Horizonte: Fórum, 2012.

ROSA, Alexandre Morais da. O hiato entre a hermenêutica filosófica e a decisão judicial. In:

STEIN, Ernildo, STRECK, Lenio Luiz (orgs.). Hermenêutica e epistemologia: 50 anos de Verdade e Método. Porto Alegre: Livraria do advogado, 2011.p.127-132.

ROXIN, Claus. Tem futuro o Direito Penal?. Revista dos Tribunais. São Paulo, vol. 790. p. 400-412, 2001.

STRECK, Lenio Luiz. Verdade e consenso. 3 ed. Porto Alegre: Livraria do Advogado, 2009. 
Hermenêutica jurídica $\mathbf{e}(\mathbf{m})$ crise: uma exploração hermenêutica da construção do Direito. Porto Alegre: Livraria do Advogado, 1999.

Compreender o Direito: desvelando as obviedades do discurso jurídico. São Paulo: Revista dos Tribunais, 2013.

Da proibição de excesso (Übermassverbot) à proibição de proteção deficiente (Untermassverbot): de como não há blindagem contra normas penais inconstitucionais. Revista do Instituto de Hermenêutica Jurídica, Porto Alegre, vol. 1, n. 2, p. 232-254, 2004.

STRECK, Lenio Luiz; OLIVEIRA, Rafael Tomaz de. O que é isto - as garantias processuais penais?. Porto Alegre: Livraria do Advogado, 2012.

WARAT, Luiz Alberto. Introdução geral ao direito. vol. 1. Porto Alegre: Sergio Antonio Fabris Editor, 1994.

WOLKMER, Antonio Carlos. Ideologia, Estado e Direito. 4 ed. São Paulo: Revista dos Tribunais, 2003.

ZAFFARONI, Eugenio Raúl. Em busca das penas perdidas. 2 ed. Rio de Janeiro: Revan, 1996.

ZOLA, Émile; BARBOSA, Rui. Eu Acuso!: o Processo do Capitão Dreyfus. São Paulo: Hedra, 2007. 